\title{
LOS CRONOCIDAS*
}

\section{Denis Grozdanovitch**}

Boswell: Acabamos por hartarnos de estar ociosos. Johnson: Ello ocurre, señor, porque necesitamos la companía de los otros, que están ocupados; pero si todos estuviéramos ociosos, no habría hastio; nos distraeríamos unos con otros.

\section{Muy a menudo voy por la tarde a la} sesión de las cuatro de la cinemateca de Chaillot. Allí encuentro regularmente a la misma pandilla de viejos cinéfilos con la cual no me mezclo (al menos todavía), pero observo subrepticiamente. Para ellos, habría que inventar una nueva expresión equivalente a "ratón de biblioteca": acaso ratón calvo de cinemateca... Barbudos, descuidados, cubiertos con sus viejos abrigos deformados salpicados de briznas de tabaco, en la boca pipas o colillas a medio apagar balanceándose en el labio inferior, oprimidos por las bufandas raídas y sucias que se enroscan alrededor de una corbata descolorida, mal vestidos con su pantalón informe de donde salen, en la cintura, faldones de camisa de otra época, provistos casi todos de portafolios de cuero ajados y abultados, atiborrados de periódicos, de revistas especializadas, de libros semirrotos, de cuadernos desportillados, y muy a menudo también, de una gran cantidad de objetos más o menos heteróclitos del tipo de soldados de plomo o trenes eléctricos en miniatura -que cambian y trafican febrilmente antes y después de las sesionesellos llegan cotidianamente puntuales a la cita. Es díficil saber si desempeñan un oficio o alguna función social; todos parecen disponer libre-

*** Traducción de Nilda Ibarguren.

** Escritor francés. 
Denis Grozdanovitch

mente de su tiempo. Casi todos son muy pálidos y se adivina que pasan la mayor parte de su tiempo metidos en las bibliotecas, en los baratillos y en las salas de cine. A fuerza de estar confrontados con los caracteres de imprenta y con la reverberación de los proyectores de ilusiones, sus ojos están rojos, dilatados, perdidos en el vacío. A la luz del día, sobre todo si hay sol, es fácil advertir que su mirada no se adapta al exterior. Después de estas sesiones, ellos regresan tal cual, del brazo, conversando en voz baja como conspiradores a propósito de las diferentes versiones (ellos las conocen todas), de los nombres de los actores, de sus méritos respectivos, volviéndose a veces vehementes, irritándose y defendiendo con una inspiración lírica que ya no controlan, el prestigio de uno de sus favoritos denigrado por los compañeros -su portafolios bamboleando en una mano, la visera de su gorra inclinada sobre los ojos ligeramente extraviados a fin de evitar la excesiva claridad de lo real. Se adivina que se dirigen hacia cuartos abuhardillados -colmados de libros, de discos, de pequeños objetos decorativos, de fotos, de periódicos y de pinturas apilados en los rincones-donde rehogan, en una sartén completamente negra y que huele a grasa, sobre un viejo hornillo que han heredado, su comida de viejos maniáticos marginales. Entre ellos, algunas mujeres: delgadas, de rostros demacrados, con lentes, sus ojos miopes perdidos en un halo donde vaga su mirada extraviada... Casi no hablan, apartándose siempre, y desaparecen de pronto tan discretamente como aparecieron, sombras clandestinas de la existencia...

Se siente que la mayoría de ellos no se ha confrontado con las peripecias o las turbulencias eventuales de la vida sino a través de la refracción de lo ficticio: son amantes de sueños...

Tomo conciencia de que estas gentes son casi las mismas que venían a jugar al billar, a las cartas y al ajedrez a la academia Roger-Conti, en la plaza de Termes, en los tiempos en que yo pasaba allí mis tardes. Me acuerdo de esas largas horas indefinidamente prolongadas, bajo la pobre luz de las lámparas colgadas muy alto, en medio del humo de los cigarros -que, en cada mesa y en los ceniceros colocados sobre el borde de los billares, parecían otros tantos minúsculos fuegos propiciatorios dedicados al dios de la suerte- en el semisilencio murmurante, punteado a intervalos regulares por los altercados de los jugadores de tarot y por el 


\section{LOS CRONOCIDAS}

ligero entrechoque de las bolas brillantes sobre el paño verde, entre esta asamblea de desclasados excéntricos, de edades y extracciones variadas: jóvenes desocupados cínicos o resignados, jubilados planificadores y reaccionarios, proxenetas jactanciosos e hipócritas, pequeños jugadores profesionales que van viviendo de sus ganancias, taimados y estafadores, rentistas plácidos y descreídos, vagos indolentes y filósofos... todos ligeramente chiflados, peculiares, provistos de extravagantes manías, de molestos tics nerviosos, adornando sus monólogos egocéntricos con expresiones curiosas fabricadas de cualquier modo, pescadas aquí y allá al azar de sus lecturas autodidactas; disimulando todos más o menos bien un secreto orgullo megalomaníaco que se revelaba en ciertos momentos de crisis: si una de sus victorias era discutida en el plano táctico, si su vencedor eventual exhibía una satisfacción demasiado evidente, o si una conversación cualquiera venía a tocar una de sus manías favoritas. Ocasiones gracias a las cuales se desencadenaba una serie de sarcasmos confusos que ellos creían brillantes, una serie de sentencias abstrusas que imaginaban definitivas, adornando el conjunto con consideraciones generales pedantes que sobrepasaban ampliamente su objeto y de las cuales no se comprendía ni jota, pero cuya rara pertinencia se podía presentir por las risitas burlonas que subrayaban sus momentos culminantes-ellos revelaban de repente (la mayoría de las veces con gran estupefacción del recién llegado que había tenido la audacia de contrariar su estrategia preferida, sin ponerse siquiera en guardia, y de "hacerlos polvo" con toda inocencia...) su inmensa piedad por la multitud de quienes habían cometido demasiado a menudo el funesto error de desdeñar su punto de vista.

Mis compañeros de ajedrez, principalmente, ofrecían una asombrosa galería de retratos. Uno de ellos, el señor Huber, viejo profesor austríaco, pequeñito, semi calvo, por lo general en pantaloncitos de golf, nunca amable, haciendo juegos con los ojos siempre enojados detrás de pequeños lentes ovales de armazón dorado, íntimamente convencido de ser un desconocido genio del tablero, tenía la costumbre, cuando uno de nosotros, jóvenes jugadores, osaba lanzar un asalto intempestivo contra el blocao ultra cerrado de su enroque, de chillar con su acento germánico marcado y su histérica voz de falsete (lo que le causaba el regaño de toda la sala): Ach, la cheunesse franceze et catholik! Wunderbar, la pelle 
Denis Grozdanovitch

cheunesse innocente! Se encogía entonces sobre sí mismo unos instantes, luego -brincando literalmente de su silla- tomaba al vuelo un alfil que hacía saltar de su casilla de salida como un diablo de una caja, para hacerlo aterrizar estrepitosamente justo en medio de nuestro ataque que se veía con ello invariablemente desmantelado, y exclamaba (provocando nuevas protestas de la asamblea perturbada): que dites-fou de cela, cheune hóme? Ach! Ce n'est pas afec des ruses de poy-scouts que fous desarçonnerez le fieil Houbeur! Y se enfurruñaba de nuevo en su silla hasta la próxima alerta.

Rosenfeld, el judío gordo, dulce y soñador, de una amabilidad un tanto obsequiosa, con el sombrero eternamente apretado en la cabeza, cuando aceptaba jugar con nosotros -prefiriendo el resto del tiempo sentarse junto a las mesas donde ya había partidos iniciados para comentarlos con observaciones sardónicas- y si se daba el caso de que lo pusiéramos un poquito en dificultad, comenzaba a frotarse el mentón reflexionando largamente, gesticulando dolorosamente y luego murmurando lentamente: "Entonces, mi querido señor, usted me pone verdaderamente en aprietos... sí, sí, estoy muy confuso... ¿Cómo voy a salir de esta trampa?" -un silencio, luego de nuevo-:" iDios, que malo es conmigo! iAh! ya no sé cómo hacer... Es muy feo lo que me hace, inunca hubiera creído eso de usted, mi querido señor, me asombra!" Y se lamentaba así un largo rato, luego, resignado, con un amplio gesto de impotencia, suspiraba: "Bueno, en fin, tengo que hacer alguna jugada, no? Veo que usted se impacienta... isí, sí, lo veo! Y ya que es preciso que juegue, no encuentro por desgracia nada mejor para hacer que iesto!" Y muy despacito, sin levantar la pieza mal sujetada con una mano, empujaba hacia usted un peón aislado cuya posición había parecido hasta el momento completamente anodina, pero que se revelaría, cuatro o cinco minutos después, como la clave de un estrangulamiento irremediable que lo forzaba a usted al abandono, lo cual le hacía exclamar: "iAh! iPero entonces...! ¿Usted no lo había visto? Ah, tuve la suerte de encontarlo distraído hoy. iSí, sí, tuve mucha suerte! Créame que estoy desolado, querido señor. Acepte, juguemos otra partida; estoy seguro de que a ésa la ganará fácilmente. Usted es joven y mucho mejor que yo. Sí, sí, estoy seguro de ello." Y el 


\section{LOS CRONOCIDAS}

mismo guión se repetía de manera casi idéntica sin que pudiéramos ganarle jamás una sola partida a Rosenfeld -ique era muy fuerte!

Moullimard, gran zangolotino, algo dandy, siempre munido de su boquilla, que se sacaba elegantemente de la boca para burlarse mejor de nosotros, circulando entre las mesas sin dejar de bromear, estaba constantemente en busca de una posición estratégica desesperada. Una vez que la localizaba, usando sarcasmos apropiados obligaba casi al náufrago a cederle el lugar, y con algunos golpes que semejaban pases mágicos, recomponía la situación y sacaba ventaja -desinteresándose entonces de ella y prefiriendo abandonar la posición reconquistada al jugador inicial que, por otra parte, se afanaba casi en seguida en arruinarla metódicamente de nuevo, no habiendo entendido absolutamente nada de la manera en que Moullimard lo había sacado de apuros. Ahora bien, lo más extraño de este especialista en salvataje, único verdadero talento ajedrecístico entre nosotros, era que si se lo llegaba a obligar a termimar alguna de las partidas que había recuperado del desastre, se mostraba a su vez, ahora que ya no estaba acorralado, incapaz de conducirla a buen término, enredándose en combinaciones tan complicadas que terminaban por anularse a sí mismas y lo arrastraban a una derrota lamentable ante aquellos de los que tanto se había mofado anteriormente.

Un último, Tony -presumido pied noir, ${ }^{1}$ siempre de punta en blanco, jugando al gran señor, adulado por las secretarias que venían a tomar una copa al bar, emergía hacia las cinco de las carreras de Longchamp o de Auteuil, donde acababa por lo regular de "ocasionar una desgracia", exhibiendo fajos de billetes de banco que sacaba del bolsillo trasero de su pantalón para hacérnoslos oler, luciendo cada día un fular diferente (del tipo fantasía, que incita inmediatamente a la melancolía)- había puesto a punto una temible táctica en caso de derrota: fingiendo exasperarse y comenzando una disputa con uno de los espectadores que indefectiblemente estaba allí para recordarle el deber del juego limpio, volviendo además la cabeza para hacerlo, no seguía jugando sino que golpeaba con violencia las piezas sobre el tablero, como si se desinteresara de la partida, pero sin omitir sin embargo ponerlas, con una notable

${ }^{1}$ Francés de Argelia (T). 


\section{Denis Grozdanovitch}

habilidad, muy precisamente en la intersección de las casillas... -lo que le permitía, si no lo advertíamos en seguida, lanzar de una sola vez una combinación tanto más inesperada para él y sorprendente para nosotros, cuanto que la pieza clave provenía de una casilla donde no habría debido estar nunca... Si alguien le hacía notar sin embargo la cosa, se enfadaba tanto que se consideraba libre, herido en su honor de caballero (y más herido aún por estar, según él, mal entablada la partida), para abandonarnos con desdén en lo que él calificaba entonces de "jueguito lamentable".

Hoy rememoro, más bien con cierto asombro, esas horas infinitas, sustraídas del mundo ordinario, en que, con los ojos clavados en los casilleros blancos y negros de eso que se había convertido para nosotros en un verdadero universo paralelo, luchábamos paso a paso -desesperadamente, como si nuestras vidas dependiesen de ello- a fin de asegurar la supremacía estratégica, adquirida al precio de argumentaciones ábstractas insensatas y agotadoras, de los ejércitos -extrañamente inertes en sí mismos, aunque animados de fogosos movimientos dinámicos por nuestras imaginaciones obnubiladas-de esas tristes estatuillas de madera barnizada, ensuciada por miles de millones de caricias.

Existe en París una multitud de sitios donde persevera en su ser esta población, sin otra ambición que la de gozar día a día de los pequeños placeres que ha logrado reservarse, un poco al margen de la marcha del mundo: el muelle del Sena, hipódromos, salas de juegos clandestinos, academias de billar, clubes de ajedrez, de bridge, de tenis, de poesía, institutos de estudios abstrusos de todo tipo, trastiendas oscuras donde se cambian estampillas raras, viejos juguetes remendados, soldados de plomo pintarrajeados, medallas antiguas, pipas de todos los países, hachas prehistóricas, talismanes, fotos de ovnis, o qué se yo qué más... Hasta cápsulas de sodas que algunos coleccionan. Están también las citas de los fanáticos de la petanca, ${ }^{2}$ que se han vuelto tan consustanciales de los jardines y de los barrios de París como sus palomos, las guaridas de jugadores de 42 lo de yam que, durante jornadas enteras, nunca se cansan de experimentar la pequeña sacudida emocional provocada por la ilusión

${ }^{2}$ Especie de juego de bolos (T). 


\section{LOS CRONOCIDAS}

fugitiva de haber sido favorecidos por el destino mediante un feliz golpe de suerte... Y además, naturalmente, centenas, millares de cafés donde se estancan -en la media luz de los espejos corroídos y brumosos, en el suave bienestar del vermouth que se bebe despaciosamente en pequeñas copas, de los gauloises que se encadenan sin apagarlos, de los chistes idénticos eternamente repetidos y del espeso paño de las mesas donde se abaten las figuras familiares- los innumerables jugadores de baraja de las largas tardes parisinas...

En sus Nuits de Paris, Restif de la Bretonne lanza invectivas contra esta ralea de inactivos, aparentemente más numerosa en su época que en la nuestra y que él llama los "cronocidas". Describe largamente lo que considera como su decadencia y les prescribe el trabajo como fortificante, como antídoto para lo que cree que es su malvivir. Dicho esto, Restif, que tenía -subrayémoslo- bastantes razones para predicar la moral convencional a efectos de hacer olvidar su conducta libertina, no habría podido imaginar por cierto, en tiempos de la Revolución Francesa -a la que asistió como espectador y nos describió-que llegaría alguna vez una época semejante a la nuestra; una época en la que, como lo dice de manera excelente Julien Gracq (en alguna parte de sus Lettrines), hubiera tantos brazos y voluntades dispuestos al cambio y transformación del mundo, y tan pocas miradas para su simple contemplación, que se llegara por ello a decretar algo así como "la eminente dignidad de los perezosos". Por otra parte, ihubiera reaccionado Restif como lo hace, él, el flâneur de deux rives si alguna vez hubiera sabido lo que significaría un día la industrialización a ultranza, la estandardización y la uniformidad del trabajo, de las costumbres y de las conciencias? ¿Y quién pues habría podido en su época prever que esta famosa Revolución Francesa tendría por efecto ulterior el reforzamiento de los valores que había querido combatir? ¿Quién pues habría predicho la reaparición de los sufrimientos redentores caros a la cristiandad, bajo la forma del Trabajo elevado al rango de dogma intangible?; ique este mismo trabajo, acelerado y propagado, en absoluto disminuido por las máquinas, conocería tal expansión, tal velocidad incontrolada, que se tornaría estéril, hasta peligroso para la humanidad?; ique esta superproductividad desarrollaría una agitacióm basta tal punto privada de sentido, que una mayoría de 
Denis Grozdanovitch

hombres ya no haría, bajo pretexto de trabajar, más que sacrificar la mayor parte de las horas de su vida a un aburrimiento aniquilador y a cambio de bienes materiales cada vez más dudosos?; ¿que el consumo mismo de esos bienes materiales supermutiplicados se convertiría en una suerte de trabajo casi obligatorio?; ¿que, por último pues, la resistencia consciente o inconsciente a este engranaje comenzaría a ser casi heroica, ascética -que en el sentido en que Restif lo había entendido en su época, serían justamente, por el contrario, los trabajadores honestos quienes se transformarían en "cronocidas"... Sí, Restif -que gustaba de tomarse su tiempo para curiosear en los muelles del Sena a fin de descubrir cualquier novedad: libro, joven criada amable y no muy esquiva, viejo vituperador o bandas de "bribonzuelos" para reprender- ¿habría imaginado alguna vez que nosotros, parisinos de fines del siglo $\mathrm{XX}$, nos tornaríamos casi incapaces de experimentar todavía la simple, muy simple, sensación de existir -tontamente, con arrobo- a semejanza de los peces que, para mantenerse en la corriente, no tienen más que dar un "ligero y exacto coletazo compensador"?, ¿que los raros supervivientes que conservaran un resplandor de lucidez en esta alienación progresiva, terminarían ellos mismos - generosamente llevados por su afán de convencer-por entregarse, para predicarnos la despreocupación a metódicas y laboriosas argumentaciones?

No obstante, a fines del siglo pasado, Robert Louis Stevenson, sin duda uno de los seres más perspicaces que hayan existido, estaba humildemente tentado de hacer ver que los ociosos poseían algunos derechos, entre ellos el de ser tolerados y no molestados, perseguidos, incluso por aquellos cuya complexión misma y temperamento insoslayable los llevaba, de todos modos y a todas luces, a activarse y producir. Escuchemos lo que nos declara al comienzo de su Apologie des oisifs:

Hoy, que todo el mundo está obligado -bajo pena de una condena en rebeldía por crimen de lesa respetabilidad- a abrazar alguna profesión lucrativa, y trabajar en ella con algo que se parezca al entusiasmo, una denuncia de la parte contraria -la que se satisface con lo que tiene, y reivindica el mantenerse como espectadorasabe un poco a bravata, si no a fanfarronada. No debería ser así, 


\section{LOS CRONOCIDAS}

sin embargo. El ocio -como se lo llama- que no consiste en no hacer nada sino en hacer mucho de lo que no está reconocido en los formularios dogmáticos de la clase dirigente, tiene tanto derecho a declarar su posición como la misma industria. Es preciso reconocer que la presencia de personas que rehúsan participar en la gran carrera de handicap por la ganancia de piezas de "sixpenny" es a la vez un insulto y un desencanto para los que se inscriben en ella. Un buen muchacho (como tantos que hemos visto) saca fuerzas de flaqueza, vota por los "sixpence" y, para recurrir al énfasis de un americanismo, "va a fondo". ¿Puede uno asombrarse de su resentimiento si, mientras él se desloma desesperadamente partiendo piedras en el camino, ve no lejos, en los prados, personas tendidas al fresco, con un pañuelo en las orejas y un vaso al alcance de la mano?

Stevenson observa con justa razón que los ociosos raramente están inactivos, que simplemente se consagran a actividades que las autoridades de turno consideran inútiles, incluso perjudiciales; condena a la que se expone por cierto a su vez la redacción de este texto, (he tenido mucho miedo de ello...) Oblomov -sin duda el perezoso más célebre de la literatura occidental, y en cuyo comportamiento se ha reconocido en parte la famosa intelligentsia de la época, al punto de consagrarle una nueva palabra de la lengua rusa: ioblomovtschina! Oblomov, es un inactivo declarado. Pero aquellos que trato de evocar aquí, no pueden ser convictos de oblomovismo, muy por el contrario. Sin embargo, ellos comparten con él una cualidad muy apreciable: tampoco se les puede reprochar que, en virtud de su incapacidad o su rechazo a participar de la histeria planificadora y activista de la sociedad contemporanéa, agreguen algún absurdo o confusión suplementaria (¿no es mucho ya?). Además, esta actitud, más instintiva que reflexiva, los lleva, más a menudo de lo que se podría esperar, a extremos casi heroicos: al no llegar a adaptarse a este imperativo categórico que quiere que placer y trabajo estén claramente disociados, prefieren casi siempre prescindir de lo necesario para consagrarse a lo superfluo. Por ventura, en forma paralela la sociedad actual -y principalmente por la evolución ultraespecia- 
Denis Grozdanovitch

lizada de la ciencia- ha comenzado a hacer cada vez más delgada, si no indiscernible en muchas ocasiones, la frontera que separa a los extravagantes que somos nosotros, de los individuos que ella puede legítimamente considerar dignos de respeto. Parece incluso que no puede ya arriesgarse mucho a intentar una discriminación entre ellos. Me han referido, en efecto, que las autoridades de la CNRS tuvieron muy recientemente la veleidad de sancionar a uno de los investigadores que estaban bajo su dependencia -el cual estaba, excepto en lo que concernía a sus emolumentos, casi "espectralizado". Ahora bien -pese al hecho de que el mismo interesado no consideraba a la sanción totalmente inicua en la medida en que, como lo reconocía sin rodeos, estaba perfectamente consciente de haber tirado demasiado de la cuerda- todos sus colegas investigadores se coaligaron en un gran impulso generoso para obtener su rehabilitación en el seno del organismo, logrando de paso hacer admitir este precepto deontológico que sin dudas sentará en adelante jurisprudencia ante las instancias superiores: "que un investigador está obligado a buscar, ino a encontrar!" Se aprecia en qué medida este acontecimiento, que anuncia quizá el comienzo de un alivio en lo que nos concierne y -iquién sabe?- a lo mejor hasta un reconocimiento oficial de nuestras ocupaciones, puede parecernos tranquilizador. Permítaseme evocar algunos recuerdos a este respecto.

En la época en que yo era un joven jugador de tenis, pasablemente dotado, y fui requerido por la federación para participar con algunos camaradas en un entrenamiento semanal en un gran club parisino, más o menos oficialmente, un experto en balística, miope como un topo, el bravo señor Pelletier, venía a explicarnos en el pizarrón, con esquemas de apoyo, la probable trayectoria de las pelotas y su previsible rebote según los efectos y la potencia del golpe que le imprimiéramos. Este sabio, que no había tocado una raqueta en su vida, se mostraba estupefacto cuando le probábamos con la práctica que una pelota podía muy bien tomar una trayectoria o poner de manifiesto un rebote que su teoría había decretado imposibles. Pero como no era terco -era ante todo un investigador en estado puro- una vez pasada la sorpresa, se inclinaba ante los hechos con un candor maravillado -a veces hasta con entusiasmo- y regresaba a sus cálculos a fin de elucidar el curioso fenómeno. 


\section{LOS CRONOCIDAS}

Más tarde, cuando viajaba regularmente al principado de Mónaco, me alojaba en un minúsculo hotel oculto en un callejón estrecho y oscuro, donde vegetaban los últimos artesanos y pequeños comercios que databan de la época de Marcel Pagnol. Allí encontraba yo ineluctablemente a dos profesores de matemáticas jubilados, Marechal y Couturier, cuyos magros subsidios les permitían conservar un cuarto a cada uno en el desván y comer en el hotel que hacia las veces de casa de huéspedes. Esos viejos señores con trayectorias muy respetables, aunque de ordinario un poco descuidados en sus trajes gastados que databan de épocas antediluvianas, pasaban todo el tiempo en conversaciones matemáticas increiblemente abstrusas y complejas, cuchicheando y dibujando sobre los manteles de papel esquemas herméticos que recortaban enseguida cuidadosamente para ocultarlos en su viejo portafolios de cuero, lanzando miradas inquietas y recelosas hacia los vanos de las puertas... Un agente secreto los hubiera tomado sin duda por nostálgicos anarquistas de retaguardia que se afanaban por fabricar una última bomba vengadora. Ahora bien, si de bomba se hubiera tratado, no podría ser otra que la que explotaría en la primera plana de los periódicos sensacionalistas al día siguiente de la gran noche en que ellos hicieran por fin saltar la banca del casino con ayuda de una de las martingalas milagrosas que perfeccionaban incansablemente en secreto desde hacía años, y cuya exactitud iban a verificar cada noche en la ruleta -siempre a un tris de resultar, nunca completamente a punto, iay!-vistiendo para hacerlo dos magníficos esmoquines comprados a plazos y que parecían cuidar como a la niña de sus ojos. Esas interminables discusiones los hacían entretenerse a veces en la comida más allá de la hora establecida; se les presentaba entonces su respectiva nota, que ellos tenían la costumbre de calcular por separado cada día para agregarle o restarle las sumas que parecían tener en litigio, abismándose entonces ambos en series de operaciones inverosímiles, enredándose y no llegando nunca a ponerse de acuerdo, hasta que Angelo, el amable y agudo jefe de comedor, que los conocía bien, viniera en su ayuda e hiciera el cálculo mentalmente. Los vi así durante muchos años, antes de saber que uno de ellos, Marechal, había sucumbido a una crisis cardíaca en el hotel algunas horas después de haber ganado al fin una suma bastante importante en la 
Denis Grozdanovitch

ruleta, pero de una manera totalmente fortuita en la medida en que Couturier, que normalmente era el jugador del equipo y cuya vista comenzaba a disminuir, habiendo leído mal en el cartoncito que consultaba a escondidas las cifras de su combinación del momento, había jugado un número ligeramente diferente del previsto. Esta buena fortuna, fuera de toda previsión y tan ajena a los laboriosos esfuerzos de los años precedentes, había fulminado a Marechal y tornado inconsolable a Couturier, quien, según Angelo, había retornado a Tourcoing, de donde era originario, a terminar melancólicamente sus días, y había donado la suma tan indebidamente ganada a las obras de Nuestra Señora de Mónaco...

Mi abuelo, también jugador empedernido aunque no del todo científico y que perdió en una sola noche la pequeña fortuna que había amasado en Londres entre las dos guerras, mantuvo luego durante muchos años a un sabio austríaco que vivía en una de las piezas del fondo del departamento, donde había instalado -según mi madre y sus hermanas, admitidas a veces a contemplar el conjunto fascinante- una red muy complicada de pequeñas montañas rusas hechas con módulos de ensamblaje tipo meccano, sobre cuyas pendientes circulaba una bola de plomo cromado que, una vez soltada desde la cima más alta del circuito, regresaba casi a su punto de partida (a diez o quince centímetros de éste) sin llegar nunca a cerrar íntegramente el circuito. Este eminente sabio-que terminó por desaparecer un buen día, no sin antes haber iniciado, tal como lo presentíamos, a mi abuela en los gozos y misterios de la física compensatoria en un estilo, así lo espero por ella, menos mecánico que el de sus experiencias habituales- buscaba el movimiento perpetuo...

El gran matemático Koenig había calculado que la celdilla ideal no era exactamente la que las abejas edificaban inocentemente en su colmena; propuso entonces un modelo ligeramente mejorado que interesó incluso a algunos apicultores, sin lograr - hay que decirlo- que lo adoptaran, hasta que otro gran sabio, Cramer, se dio cuenta de que Koenig se había equivocado y que las dimensiones de la celdilla primordial -la que las abejas utilizaban desde siempre y que un tercer sabio, Maraldi, había vuelto a medir muy cuidadosamente entre tanto- eran con mucho las más perfectas posibles. iTodo volvía a estar en orden!

Pero el más ejemplar entre todos los que tuve ocasión de encontrar 


\section{LOS CRONOCIDAS}

seguirá siendo, sin ninguna duda, Samuel Benguigui. Éste habitaba en Pau, en el último piso de una moderna torre construida en el borde de un acantilado que dominaba desde una centena de metros el valle del Garona. A la edad de setenta años, retirado de la función pública, Benguigui se había vuelto muy versado en aerodinámica espacial, y pasaba largos ratos haciendo sesudos cálculos, luego dibujando los planos del avión que, hasta donde recuerdo, eran en sí mismos muy estéticos. Concluida cierta fase preparatoria que podía tomar una o dos mañanas, Benguigui pasaba a la construcción propiamente dicha del artefacto, cuya insigne particularidad consistía en estar confeccionado exclusivamente en papel (por lo general con viejos números del Sud-Ouest), estando prohibido incluso el cartón. Terminada la fabricación, Benguigui, que era muy metódico, comenzaba por tomar una foto del prototipo, y luego, si el tiempo se prestaba para ello, pasaba a la fase final y solemne, resultado de los esfuerzos de los días precedentes, iel lanzamiento! Cuando yo estaba presente, como ocurría a menudo en cierta época, Samuel iba a buscar una botella de espumoso y brindábamos; luego, aproximándose con pasos contados hasta el borde del balcón que, como ya dije, dominaba una vasta extensión, lanzaba la nave de papel al espacio abierto con un gesto amplio y un poco enfático. Sentándose entonces en un sillón de mimbre reservado a tal efecto, envuelto en una manta y con un gorro encasquetado hasta las orejas, Benguigui supervisaba las evoluciones de su "avión", las que podían variar entre la caída instantánea y las dos o tres horas de elegante planear sobre el Garona y hacia las primeras estribaciones de los Pirineos que nos hacían frente en su altivo esplendor condescendiente -en un caso tan favorable, seguíamos las últimas evoluciones aguzando la visión con los prismáticos hasta que la endeble armazón desapareciera detrás de una cortina de árboles... Supe después que Samuel Benguigui no era único en su especie y que esta actividad, bastante extendida a través del mundo, se llamaba i"papidurología"!

En último término, me gustaría todavía señalar la creación bastante reciente de una asociación metropolitana de trivialistas, que reúne ya algunas centenas de adherentes en todo el país. Los miembros de esta institución muy respetable se encuentran a horas convenidas en cual- 


\section{Denis Grozdanovitch}

quier lugar -paradas de autobús, pies de columnas Morris, fondas de estaciones ferroviarias, etcétera- pero, y éste es el aspecto apasionante del asunto, sin tener ningún motivo preciso para encontrarse ni nada especial que decirse; siendo esta última condición, según lo que he podido comprender, totalmente deseable. Tampoco es obligatorio asistir efectivamente a la cita, aunque esta última cláusula sea uno de los únicos motivos de litigio en las raras discusiones que se generan a veces entre los trivialistas, cuando tienen oportunidad de encontrarse. De todas maneras, la condición de trivialista no implica ninguna regla definida; como lo declara con firmeza y entusiasmo su presidente y fundador: "Se es trivialista o no se es; iy se acabó!" El gran congreso, que reúne teóricamente a todos los miembros en el mismo lugar durante algunos días, es el punto culminante del año trivialístico. Los congresos de estos últimos años tuvieron grandes logros. Según una pareja de trivialistas que yo conozco, la principal actividad de los participantes consiste en ir a recibir a los que llegan a la estación lo más cordialmente posible y acompañarlos luego a su hotel profiriendo gran cantidad de interjecciones entusiastas a fin de salir al paso de toda veleidad de información sobre el orden del día, por temor de ciertos nuevos miembros todavía no compenetrados del espíritu institucional. En el congreso mismo, no está previsto naturalmente ningún tema en particular, y cada uno está requerido de intervenir exclusivamente cuando a él le plazca, y de preferencia cortando la palabra a aquellos cuyo discurso comience a apartarse peligrosamente de la más estricta trivialidad. Después, por lo general, luego de algunos días de discusiones desordenadas donde cada uno participa activamente de la algarabía general sin estar por tanto obligados a escuchar realmente a su interlocutor, los congresistas se separan dándose citas particulares para el año en curso -la mayor parte de las cuales no se cumple porque casi todos los trivialistas anotan las direcciones en pedazos de papel sueltos que rápidamente se extravían. Como lo declara también su presidente: "La asociación de los trivialistas no quiere distinguirse en nada de la vida en general, salvo, justamente, por la voluntad de sus miembros de tener una conciencia aguda de esto, y por su deseo de tranquilizarse mutuamente -y lo más posible- a este respecto!"

En realidad, esta población de excéntricos y de originales, de diletan- 


\section{LOS CRONOCIDAS}

tes, de "cronocidas" o de trivialistas -irreductible en sí misma- ha sobrevivido siempre un poco en todas partes, cualesquiera sean los regímenes, los acontecimientos y los trastornos -no lejos de la actualidad pero justo al lado, paralelamenre a ella, podría decirse; suave pero obstinadamente indiferente a lo que no tenía que ver con sus manías. Cuando yo era adolescente y mi padre me veía preocupado por no sé qué giro tomado por los acontecimientos, tenía la costumbre de repetirme: "Piensa, hijito, que en el curso de todas las circunstancias de la historia ha habido pescadores de caña." Ahora bien, Jünger cuenta en su Diario de Ocupación, que leí mucho más tarde, que entrando en París abandonado por el éxodo, encaramado sobre uno de los carros de su compañía, ve al pasar sobre el puente de la Concordia, más abajo de los pilares del mismo, a un tipo muy apacible que pesca fumando tranquilamente su pipa. Por otra parte, si entramos en no importa cuál museo de arte asiático antiguo y nos dirigimos hacia las colecciones chinas, encontraremos por cierto en algún momento, débilmente iluminado detrás de su vitrina, uno de los grandes rollos de pergamino exquisitamente pintado por alguno de esos misteriosos artistas Tch'an de los tiempos antiguos, y veremos en él, probablemente representados con sus uniformes rutilantes y multicolores, a los innumerables soldadotes temiblemente feroces de dos ejércitos rivales, enarbolando magníficas banderas pintarrajeadas sobre las que escupen fuego formidables dragones, despedazándose generosamente en combates sin cuartel. Al profundizar nuestro examen, acabaremos también por descubrir, en un rincón del rollo, por lo general disimulado detrás de una cortina de árboles, un pequeño estanque cubierto a medias por nenúfares donde viene a desembocar haciendo espuma alegremente un arroyo, que desciende de la montaña en graciosos zigzags y en cuya superficie, bajo un sauce vaporoso vecino de otros árboles coronados de frágiles flores blancas, no lejos de algunos patos meditabundos que se dejan derivar sobre la onda entre jirones de bruma, reposa una barca donde un pequeño personaje tocado con un sombrero de paja pesca sin preocuparse por nada. Y si tenemos todavía la paciencia de descifrar las notas eruditas que acompañan siempre a estas pinturas en los museos, nos enteramos de que, para los ermitaños de Tch'an, el pescador de caña (particularmente si está un poco ebrio de vino de arroz) representa el 
Denis Grozdanovitch

más perfecto símbolo de la sabiduría. Sobre uno de tales rollos, que se encuentra en el Museo Metropolitano de Nueva York, la minúscula sentencia caligrafiada en chino y que flanquea la cabeza del pescador ha sido traducida al inglés y dice así:

Right and Wrong reach not where men fish Glory and Disgrace dog the official riding his horse.

Lin Yu Tang, filósofo chino contemporáneo nos declara en su famoso libro La importancia de vivir:

Después de una larga exploración de la literatura y de la filosofía chinas, llego a la conclusión de que su más alto ideal ha sido siempre el hombre desapegado (Ta Kuan) de la vida y sabiamente desencantado. Esta sabiduría engendra una cierta grandeza de carácter, que da a cada uno la posibilidad de avanzar en la existencia con una ironía tolerante, de escapar a las tentaciones de la gloria, de la riqueza, de las proezas, y finalmente, de aceptar los acontecimientos. De este desprendimiento se derivan también el sentido de la libertad, el gusto por el vagabundeo, por el orgullo, por la indolencia. Pues sólo el sentido de la libertad y del ocio permiten alcanzar la alegría de vivir intensamente... El disfrute de una vida ociosa no cuesta caro. El verdadero gusto por el ocio se ha perdido en las clases ricas, y no se encuentra más que entre las gentes que tienen un supremo desprecio por el dinero. Proviene de una riqueza íntima del alma en un hombre que ama la vida simple y que se impacienta al tener que ganarla. Habrá siempre bastante vida para gozar de ella, para un hombre que está decidido a hacerlo.

Ahora bien, si desde el alma de los tiempos humanos, los chinos han reverenciado siempre una cierta forma de ocio, el mundo animal ofrece a nuestra admiración un ejemplo de diletantismo natural más antiguo y más perfecto aún. Parecería que el perezoso -bajo el aspecto con que podemos percibirlo en nuestros días en ciertas partes de la selva amazó- 


\section{LOS CRONOCIDAS}

nica-hubiera sobrevivido a todas las vicisitudes de la vida salvaje desde los tiempos históricos más remotos - constatación que invalida de manera decisiva la sacrosanta teoría darwiniana. ¿Cómo conciliar, en efecto, el credo del strugle for life con la fabulosa perennidad de un animal tan poco dotado para la competencia? Por otra parte, no es sin duda fortuito que sea precisamente un investigador americano, J. K. Summerville, quien haya consagrado cerca de 15 años de su vida a acechar las raras evoluciones de este despreocupado refractario en su medio natural. Para hacerlo, y como se puso de moda desde Konrad Lorenz que, en su tiempo, permaneció meses enteros sumergido hasta la cintura en un estanque cenagoso para integrarse mejor a un grupo de patos en el cual había puesto su mira, parece que Summerville trató de impregnarse totalmente de las costumbres de los perezosos -operación que rápidamente se revelaría mucho más acrobática y ascética de lo que hubiera pensado al comienzo, en la medida en que el animal permanece a veces colgado hasta 10 días seguidos de la misma rama, sin manifestar la menor veleidad por cambiar de posición (¿para dormir o para meditar?, esto sigue siendo incierto y las conclusiones de J. K. no son formales a este respecto), y no desciende de ella más que bajo el imperio de la extrema necesidad: el hambre y la defecación ("Durante el pequeño y el gran cometido, asegura J. K., él cierra los ojos con una expresión que nos atreveríamos a calificar de placer tranquilo.") Cuando el perezoso está en tierra, se toma todo su tiempo, desplazándose lentamente y cayendo frecuentemente en extrañas distracciones en cuyo transcurso, olvidándose visiblemente de su proyecto inicial, descansa cómodamente en la hierba, el vientre al sol, durmiendo o meditando de nuevo más o menos indefinidamente... En el agua, el perezoso se muestra todavía más a gusto: es el único animal de la creación que nada de espaldas; con su enorme estómago que le sirve de boya permitiéndole flotar, sólo tiene que usar sus brazos como pequeños remos para propulsarse indolentemente sobre las ondas... Por último -y tocamos con ello el aspecto sublime de las observaciones hechas en este animal- al considerar las fotos tomadas por Summerville, resulta que el perezoso, en el transcurso de todas las indolentes idas y venidas o meditaciones somnolientas que componen sus hábitos, no abandona nunca una sonrisa que no podemos 
Denis Grozdanovitch

describir de otra manera que como la expresión de una completa beatitud ("¿El perezoso sería un bienaventurado?", pregunta ansiosamente el investigador americano.)

Pero lo más sorprendente de lo que nos refiere Summerville siguen siendo las costumbres eróticas y sexuales del animal: si las aproximaciones amorosas se alargan penosamente, una vez apareados los compañeros se desenfrenan en una larga serie de espasmos frenéticos sin el menor pudor ni la menor inhibición; luego vuelven a caer -extenuados pero todavía arrebatados, en su semiletargo acostumbrado. (J. K. confiesa su perplejidad a este respecto: imanifiestan un verdadero entusiasmo o experimentan la acción de las leyes de la especie?)

De cualquier manera, el artículo donde pude recoger toda la información sobre las investigaciones de Summerville nos da a entender que, desde su regreso, el ilustre investigador tiene algunas dificultades para retornar al ritmo de la "vida activa". Parecería que J. K. no sale sino raramente de sí mismo, que sus editores se lamentan amargamente de la extrema lentịtud con la cual prosigue la redacción de su obra tan esperada, Comprender a los perezosos, y que su esposa tiene todas las dificultades del mundo para convencerlo de que tenga a bien descender de la viga maestra de la sala donde permanece agarrado jornadas enteras meditando...

Hay entre nosotros quienes pretenden ahora que entramos en la civilización del tiempo libre, que la energía desplegada hasta el presente en el mundo del trabajo será en adelante canalizada hacia un vasto universo de diversiones, que nosotros, los diletantes -dejando por ello mismo nuestro estatus de marginales, podríamos al fin, como lo desea Samuel Johnson, encontrar numerosos y nuevos compañeros de juego. Permítaseme ponerlo en duda. ¿No basta con observar el espíritu general que reina ya en las grandes realizaciones del turismo, de los clubes de vacaciones, del deporte y de la cultura de masas para comprobar que aquellos cuyo temperamento indefectible es producir y activarse no pueden, cuando se ponen de pronto a divertirse, dejar de introducir nuevamente en sus distracciones -inconscientemente al comienzo, deliberadamente después- los principios fundamentales quesiempre los han animado: eficacia, rentabilidad, profesionalismo, redención por el sufri- 
LOS CRONOCIDAS

miento? (¿Habéis tenido alguna vez la ocasión de contemplar esas nuevas gigantescas procesiones de flagelantes modernos que constituyen, a todas luces, los corredores de maratón o los corredores matinales que uno cruza en las calles, el rostro crispado por el esfuerzo, el ser orientado hacia la salvación de su alma?)

Ahora bien, querámoslo o no, esto no será nunca para nosotros, iepicúreos incurables! Incluso cuando nuestras actividades vinieran a confundirse en apariencia con las suyas, diferirían profundamente de ellas. En efecto, sería difícilmente concebible que lográramos nunca desembarazarnos de la calidad de aficionados desenvueltos que nos caracteriza. En pocas palabras, mientras nosotros continuaremos entreteniéndonos amablemente, ellos, como lo dice de manera excelente un humorista moderno, "trabajarán duro, los pobres, para divertirse".

Por lo demás, podríamos preguntarnos en qué medida la nueva sociedad del tiempo libre tolerará esta irreductible ineptitud de parte nuestra. ¿Nos permitirá dejar de lado sus competiciones y desdeñar su sed de marcas? ¿No buscará apartar, y luego confundir a los aficionados clandestinos? A continuación de lo cual, éstos serían suave y firmemente reubicados en el recto camino del tiempo bien administrado. iSe sabe con qué atenta solicitud la colectividad moderna trae nuevamente consigo a las ovejas descarriadas!

En una circunstancia tan siniestra, ¿qué alternativa se nos ofrecerá aún? ¿Deberemos profesar a escondidas, disimulados dentro de nuevas catacumbas? ¿Deberemos comunicarnos mediante mensajes cifrados y darnos a conocer? ¿Tendremos todavía el recurso de refugiarnos en esas comarcas (al menos por el lapso en que ellas mismas continúen existiendo) que, en todas las épocas, fueron la patria de los excéntricos: las islas británicas? ¿Conoceremos entonces una existencia semejante a la de aquel Jenkins, mencionado por Edith Sitwell en su libro Los excéntricos ingleses y que, "en esta fecha, en su año 157, se activaba siempre. Su biógrafo nos enseña en un arrebato de admiración", prosigue ella, "que este personaje pasó el último siglo de su vida pescando y que se lo veía a menudo nadar en las orillas, los pelos de su barba flotando como hierbas sobre las ondas del agua" $\mathrm{Al}$ menos, puedo afirmar que, muy reciente- 
Denis Grozdanovitch

mente y como esta última anécdota va a testimoniarlo, espero, la situación se presentaba tan favorable como en el pasado.

Mientras paseaba yo en un día ventoso, en pleno invierno inglés, por una calle del jardín público que domina el rebaño apretado de pequeñas casas de ladrillo rojo que conforman el barrio obrero de la ciudad de Sheffield, di, a la vuelta de un macizo que me lo había ocultado hasta entonces, con uno de los respetables súbditos de Su Majestad en pleno ejercicio. El individuo lucía un bello bigote bien recortado y estaba tocado con una gorra de tweed y cubierto con un abrigo acolchado que llevaba sobre saco y corbata. Con la pipa en la boca, sentado en una silla plegable en medio de un terreno cubierto de césped, tenía con una mano la bobina y con la otra el hilo que, en una larga curva graciosa, lo conectaba con un soberbio cometa rojo perdido en las alturas de un cielo tormentoso donde gruesas nubes cargaban a la carrera como elefantes furiosos. Como pasé delante suyo saludándolo con la cabeza, me interpeló:

- ¿Sería usted tan amable de tener esto unos instantes?

Respondí que estaría encantado y me pasó la bobina y el hilo, que tuve a fuerza de brazo, muy asombrado además de la potencia de tracción que se ejercía allí, mientras él, metiendo la mano en una especie de capacho como los que se usan para ir al mercado, sacó un termo de donde se sirvió, en un vaso metálico, un té muy caliente que mezcló con leche en un minúsculo envase de cartón sacado del bolsillo de su saco, y comenzó a beber tranquilamente en pequeños sorbos, vigilándome con el rabillo del ojo:

-iNo tan fuerte, joven, aflójelo un poco!

Luego, sacando un segundo vaso, todo abollado éste, de su capacho, me preguntó:

- ¿Un poco de té?

-Con gusto.

Una vez servido el té en el vaso que me destinaba, me lo tendió, luego volvió a agarrar la bobina y el hilo y yo bebí lentamente, parado a su lado, mientras el viento redoblaba esfuerzos como para arrancarle el hilo de las manos. Hubo un largo momento durante el cual él maniobró en 


\section{LOS CRONOCIDAS}

silencio, los ojos elevados al cielo, resistiendo con flema los asaltos venidos de lo alto. Luego, sin volver la cabeza, me dijo de repente:

-Qué tiempo maravilloso, ¿no?

Esperemos sin embargo que la evolución de las costumbres no llegue nunca a extremos tan incómodos como los evocados más arriba y que no tengamos que afrontar en el futuro, tal como estamos acostumbrados, nada más que la reprobación más o menos despreciativa de las gentes honestas que, además, cuando nos cuestionen con incredulidad, según su costumbre, a propósito de lo que consideran nuestras extrañas actividades, tengamos el ánimo de recordar lo que solía responder en similares ocasiones Ryokan, el monje loco:

...en la primavera con cien flores, en las grandes alamedas

yo juego a la pelota

si al pasar un transeúnte me pregunta le respondo:

"soy un hombre ocioso en una época de paz". 